\title{
PROJETO 5 PILARES NA CONSTRUÇÃO DO CONHECIMENTO DA ENGENHARIA CIVIL
}

\author{
Ana Flávia de C. D. Silveira ${ }^{1}$; Camila Alejandra C. Bustamante ${ }^{1}$; Chrystian C. \\ Ventura'; Maria Eduarda de O. Pereira ${ }^{1}$; Vítor F. Mendes ${ }^{1}$ \\ ${ }^{1}$ Universidade Federal de Ouro Preto
}

\section{PET Engenharia Civil, Universidade Federal de Ouro Preto, Ouro Preto, Minas Gerais}

Palavras-chave: Introdução à Engenharia Civil; Ensino de Engenharia; Calouros; Engenharia Civil.

\section{Introdução}

O projeto 5 Pilares, inspirado no projeto Vetor (SILVA et al., 2016), é coordenado pelo grupo Civil Nota 5 e desenvolvido na disciplina de Introdução à Engenharia Civil para os calouros do curso na Universidade Federal de Ouro Preto (UFOP). O Civil Nota 5 é um grupo idealizado pelo PET Civil UFOP e criado em parceira com todas as demais entidades estudantis de Engenharia Civil da UFOP. O projeto completou, no segundo semestre de 2018, sua segunda edição e tem 0 objetivo de apresentar, aos discentes ingressantes na universidade, de maneira interativa e prática, o curso e as áreas de atuação de um engenheiro civil por meio da contextualização e resolução de problemas aplicados à engenharia, dado que a maioria desses alunos desconhecem as competências da profissão: atividades relacionadas a estradas, sistema de abastecimento de água e de saneamento, portos, rios, canais, barragens e diques, drenagem e irrigação, pontes e grandes estruturas, sistema de transportes, pistas de rolamento e aeroportos e edificações (BRASIL, 1966).

O projeto conta com a participação voluntária de monitores e com o desenvolvimento dos seus trabalhos em grupo, tendo foco em uma das cinco grandes áreas da Engenharia Civil: Recursos Hídricos, Infraestrutura, Estruturas, 
Geotecnia e Construções. O projeto oferece aos calouros uma experiência prática, tópico muito requisitado no mercado atual e defasado na UFOP na opinião dos alunos em geral. (MENDES et al., 2018).

\section{Metodologia}

\section{1- Fase inicial}

Com o início de cada semestre, realiza-se a divulgação do projeto 5 Pilares, visando ter monitores das 5 grandes áreas da Engenharia Civil. O grupo Civil Nota 5 opta por enviar e-mails para todos os alunos, a fim de que tomem conhecimento e desenvolvam o interesse em participar do projeto, uma vez que o programa depende de líderes de um grupo de estudantes do primeiro período. Dessa forma, a estratégia utilizada é a seleção de alunos de períodos subsequentes para que estes sejam monitores do 5 Pilares. Assim, durante as duas edições do projeto, a ferramenta para essa seleção foi desenvolvida por meio de formulários online, nos quais os interessados manifestaram a área desejada para desenvolver um trabalho e, a partir dos dados obtidos, realizouse a entrevista individual com cada um, na qual apresentaram a proposta do seu trabalho. Houve um momento para tirar dúvidas, propor sugestões e, por fim, após discussão entre os organizadores, selecionaram-se os trabalhos, bem como os monitores.

Para dar início ao projeto, efetivamente, fez-se uma apresentação deste aos alunos durante um horário reservado na aula de Introdução à Engenharia Civil. O grupo Civil Nota 5 formulou a apresentação do 5 Pilares, de modo a esclarecer aos alunos o papel do projeto, as vantagens de fazer parte dele e a história de seu desenvolvimento. Em seguida, apresentou-se de forma sucinta as 5 áreas da Engenharia Civil. Os monitores foram responsáveis por apresentar suas propostas de trabalhos com o intuito de cativar os alunos. Além disso, estes tiveram liberdade de tirar dúvidas em relação às áreas e aos trabalhos. Depois disso, realizou-se um sorteio com intuito de definir os participantes de cada trabalho. $O$ aluno sorteado teve a chance de escolher qual grupo desejava compor, desde que este ainda estivesse incompleto.

2- Fase de desenvolvimento

O projeto contou com aulas reservadas ao seu desenvolvimento, porém sua elaboração não se restringiu a elas. Através delas os grupos tiveram a liberdade 
de se reunir e de dar sequência às atividades pré-estabelecidas pelos monitores. Duas dessas aulas se destinaram a apresentação parcial e a final: a primeira com o intuito de mostrar aos professores, aos demais alunos e aos membros do grupo Civil Nota 5 o andamento das atividades; e a segunda com a finalidade de apresentar os trabalhos concluídos.

Além disso, para o desenvolvimento do projeto os monitores fizeram encontros de acordo com a necessidade e sua disponibilidade, bem como dos alunos envolvidos em cada grupo. Ademais, pelo fato de o foco dos trabalhos ser o de adquirir uma vivência mais real e prática com a Engenharia Civil, muitas vezes, fez-se necessário ir a campo para obter informações a partir das observações, o que, em sua maioria, realizou-se em horários alternativos.

Com o objetivo de facilitar a comunicação dos envolvidos no projeto e também para proporcionar um melhor acompanhamento em relação ao andamento dos trabalhos, criaram-se grupos na plataforma digital WhatsApp. Nesses grupos, estavam presentes os alunos, os monitores e alguns dos coordenadores do 5 Pilares. Durante o semestre, as conversas foram utilizadas para diversas atividades, sendo elas: a troca de conhecimentos, o compartilhamento de fotos, a marcação de reuniões e divulgação, pelos monitores, das tarefas que deveriam ser realizadas pelos alunos.

Durante a realização dos trabalhos cada grupo entregou ao professor um relatório parcial e outro final, com o objetivo de fazer com que ele tomasse conhecimento do que estava sendo desenvolvido no projeto 5 Pilares, além de disponibilizar o estudo para os demais alunos que se interessassem pelo assunto. A elaboração dos relatórios também visou familiarizar os novatos com a produção de documentos acadêmicos, algo muito requisitado nos períodos seguintes.

Com o objetivo de trazer maior visibilidade para o 5 Pilares, os professores do Departamento de Engenharia Civil (DECIV) foram convidados para assistir à apresentação final dos trabalhos.

No segundo semestre de 2018, o projeto contou com três trabalhos: "Acessibilidade das vias de acesso à UFOP", "Análise qualitativa das vias que dão acesso à UFOP" e "Patologias na construção civil". Os dois primeiros se referiam à área de Infraestrutura e o terceiro, à área de Construções.

\section{3- Acompanhamento e fase conclusiva}


A fim de acompanhar os monitores, fez-se reuniões individuais para efetuar repasses e esclarecer possíveis dúvidas acerca do projeto. Ainda, o Civil Nota 5 Ihes enviou formulários por e-mail para relatarem sobre as reuniões realizadas com seus grupos, sendo informados datas, pautas, alunos presentes, etc. Dessa forma, o Civil Nota 5 pôde auxiliar os grupos quando necessário.

O projeto 5 Pilares foi avaliado em 6,0 pontos (de um total de 10,0) na disciplina de Introdução à Engenharia Civil: 4,0 pontos foram de responsabilidade do professor da disciplina que avaliou a apresentação parcial e final do trabalho nos quesitos que envolviam os relatórios e as apresentações orais; 1,5 ponto foi destinado à avaliação do rendimento dos alunos na visão dos monitores (quesitos como presença nas reuniões, participação na execução dos trabalhos e convivência com os integrantes são preponderantes nessa avaliação); o restante - 0,5 ponto - foi destinado à autoavaliação dos grupos de trabalho. Logo, os alunos puderam se autoavaliar e avaliar cada aluno de seu grupo.

Durante todo o desenvolvimento do projeto, especialmente no final, fez-se repasses ao professor da disciplina de Introdução à Engenharia Civil, a fim de deixá-lo ciente de todo 0 andamento e mostrá-lo se o projeto repercutiu relevantemente aos alunos. Tal encaminhamento faz-se de extrema importância, uma vez que é necessário obter resultados positivos para a continuidade do 5 Pilares.

Figura 1: Fases do projeto 5 Pilares

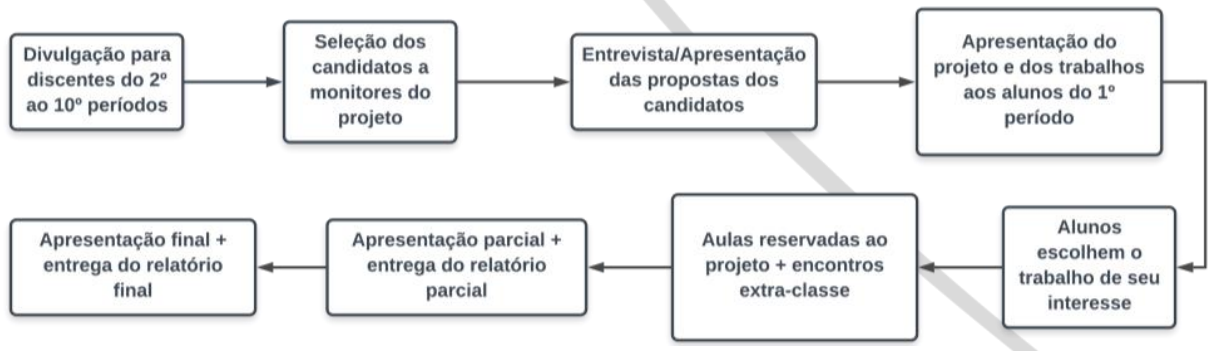

Fonte: Elaborado pelos autores

\section{Resultados e discussão}

No segundo semestre de 2018, houve uma evasão significativa de possíveis monitores, o que ocasionou um número pequeno de inscritos no projeto. O Civil Nota 5 acredita que tal situação se deve ao fato do processo seletivo de monitoria da Escola de Minas da UFOP ter ocorrido concomitantemente com o 5 Pilares. 
Acredita-se, ainda, que a divulgação para a comunidade acadêmica não foi perfeitamente estruturada, faltando informações para as pessoas se inteirarem acerca do projeto. Observou-se insegurança dos candidatos a monitores por não saberem, com clareza, o que era o projeto e por terem pouca experiência de liderança na universidade, resultando em propostas de trabalhos pouco coesas. No início do desenvolvimento do projeto, percebeu-se a falta de interesse de alguns alunos. Porém, de acordo com o feedback dado por eles e pelos monitores, tal fato alterou-se no decorrer do semestre.

Surgiram algumas indagações dos alunos sobre os trabalhos, por não se tratarem de propostas bem definidas. Além disso, questionaram o fato de desenvolverem algumas atividades sozinhos. Porém, um dos focos do projeto é desenvolver a maturidade e a autonomia dos alunos, de modo a prepará-los para a universidade.

Os alunos de Engenharia Civil da UFOP têm pouco contato com trabalhos de campo e atividades práticas nos primeiros períodos. Esse tipo de vivência, proporcionado pelo projeto 5 Pilares, permite aos estudantes um melhor entendimento do curso, além de facilitar os estudos, estimular o pensamento crítico e gerar maior interesse.

Além disso, considerando a variada rotina dos alunos, as aulas reservadas às atividades foram de extrema importância, pois permitiram a participação de todos, além de contribuírem para o entrosamento dos grupos, garantindo foco e responsabilidade com o projeto.

O acompanhamento dos monitores permitiu que os organizadores tivessem ciência dos acontecimentos e que os monitores se sentissem amparados, proporcionando-os mais segurança, já que podiam informar situações de incômodo no processo de trabalho em grupo, nas quais a coordenação poderia auxiliar.

O objetivo de trazer mais visibilidade ao projeto 5 Pilares, ao convidar os professores do DECIV para a apresentação final, foi alcançado, uma vez que muitos compareceram e mostraram interesse pelos trabalhos.

A partir dos dados obtidos no feedback, percebeu-se o interesse e a valorização dos alunos com o projeto. Além disso, alguns demonstraram interesse em ser monitores futuramente. Contudo, houve relatos de experiências não tão positivas em relação ao projeto, os quais foram devidamente analisados. 


\section{Conclusões}

Com base nas duas edições do 5 Pilares, pode-se afirmar que o projeto tem alcançado seu objetivo de forma satisfatória para os alunos em geral, professores e demais servidores da UFOP. O projeto desperta o interesse dos alunos com o curso, permitindo, já no primeiro período, que os calouros se familiarizem com alguma área, o que pode contribuir para a diminuição do índice de evasão do curso.

Por se tratar de um projeto muito novo, o 5 Pilares exige aprimoramentos, mas por meio de diálogo, pesquisa de opinião e constante atualização ele se renova a cada semestre, com ideias mais concisas e consolidadas.

\section{Referências}

BRASIL. LEI n5.194 de 24 de dezembro de 1966. Regula o exercício das profissões de Engenheiro, Arquiteto e Engenheiro Agrônomo. Disponível em: $<$ http://normativos.confea.org.br/ementas/visualiza.asp?idEmenta=266>. Acesso em: 14 jan. 2019.

SILVA, Luis Carlos de Souza et al. Projeto vetor: uma inovação de sucesso no ensino da engenharia. 2018. 17 p. Curitiba, 2018. Disponível em: <http://www.brjd.com.br/index.php/BASR/article/view/540/464>. Acesso em: 14 jan. 2019.

MENDES, V. F. et al. Análise do curso de Engenharia Civil da Universidade Federal de Ouro Preto de acordo com a percepção dos alunos. 2018. 10 p. Artigo. XLVI Congresso Brasileiro de Educação em Engenharia. Salvador, 2018. 